\title{
Radiological Spectrum of Active Sacroiliitis by Conventional Radiography and MRI
}

\author{
Kaushik R, Mital M, Thukral B, Sagar S, Singh AP, Gupta R \\ Department Of Radiodiagnosis, Subharti Medical College, Meerut
}

Received: January 13, 2020

Accepted: March 15, 2019

Published: June 30, 2020

Cite this paper:

Kaushik R, Mital M, Thukral B, Sagar S, Singh AP, Gupta R. Radiological Spectrum of Active Sacroiliitis by Conventional Radiography and MRI. Nepalese Journal of Radiology 2020;10(15):2-10.http://dx.doi.org/10.3126/ njr.v10i1.27768

\begin{abstract}
Introduction: The aim of the present study was to compare the role of Conventional Radiography and Magnetic Resonance Imaging (MRI), in diagnosis of active sacroiliitis and differentiation between inflammatory and infective sacroiliitis.

Methods: Fifty two cases of active sacroiliitis diagnosed on MRI from August 2017 to August 2019 were included in study. All the patients were subjected to conventional radiology, MRI and findings were co-related with clinical and laboratory findings. Conventional radiography was used to evaluate structural changes. MR images were evaluated for bone lesions (extent and distribution of bone marrow edema and presence of bone erosions), soft-tissue lesions (capsulitis, extra capsular fluid collections, and peri-articular muscle edema) and joint space reduction for differentiation between infective and inflammatory etiology.
\end{abstract}

Results: Conventional radiography showed sclerosis, erosion, partial and complete ankylosis. Thick capsulitis, extra capsular fluid collection, and peri-articular muscle edema were all more frequently observed in infective sacroiliitis $(\mathrm{p}<0.001)$. Iliac-dominant bone marrow edema more common in spondyloarthritis $(\mathrm{p}<0.001)$. When periarticular muscle edema was the sole predictor, unilateral sacroiliitis in spondyloarthritis was correctly identified in $79.16 \%$ of cases, and infectious sacroiliitis was correctly identified in $82.14 \%$ of cases.

Conclusions: MRI is the optimum imaging modality to diagnose active sacroiliitis. MRI plays an essential role in better demonstrating early alterations and inflammatory activity and aid in differentiation of infective and inflammatory sacroiliitis. Conventional radiography with low sensitivity can be used as a screening tool and follow-up of patients with sacroiliitis.

Key words: Ankylosis; Bone Marrow; Bursitis; Sacroiliitis; Spondyloarthritis

\section{INTRODUCTION}

Sacroiliitis can be classified as infective and inflammatory sacroiliitis. Non-infective

Correspondence to: Dr. Mital Mukta

Department of Radiodiagnosis

Subharti Medical College

Meerut, Uttar Pradesh, India

Email: muktamital@yahoo.com sacroiliitis: It includes seronegative spondyloarthropathies, gouty arthritis and rheumatoid arthritis. Seronegative (C) $\begin{aligned} & \text { Licensed under CC BY } 4.0 \text { International License which } \\ & \text { permits use, distribution and reproduction in any } \\ & \text { medium, provided the original work is properly cited }\end{aligned}$ 
spondyloarthropathies includes: Ankylosing spondylitis, Reactivearthritis, Psoriaticarthritis, Arthritis related with chronic inflammatory disease and Undifferentiated Spondyloarthritis (describes manifestations of the disease that do not meet criteria to be classified into any of the spondyloarthritides, discussed previously). Infective sacroiliitis includes: Septic arthritis and Sacroiliac tuberculosis. Most of times, the clinical diagnosis of sacroiliitis is difficult, depending substantially on the confirmation of radiological findings, where conventional $\mathrm{x}$-ray, and currently, computerized tomography (CT) and magnetic resonance imaging (MRI) assume an essential role. ${ }^{2}$ As the symptoms of sacroiliac involvement at presentation are not specific, the diagnosis of sacroiliitis is heavily dependent on confirmatory imaging. ${ }^{3}$ In this study, we aim to compare the role of Conventional Radiography and Magnetic Resonance Imaging (MRI) in diagnosis of active sacroiliitis, and differentiation between inflammatory and infective sacroiliitis..

\section{METHODS}

A prospective study design was employed with the purpose to analyse the conventional radiography and MRI in the diagnosis of active Sacroiliitis between 2017 to 2019. Patients referred to Department of Radio diagnosis \& Imaging from OPD/IPD/EMERGENCY of C.S.S. Hospital, under the ageis of N.S.C.B Subharti medical college, Meerut. Informed consent of all participants was obtained after explaining the purpose of the study. Permission to carry out the study was obtained by Institutional Ethical Committee of NSCB Subharti Medical College.

A total of 52 patients with diagnosis of active sacroiliitis were included for the study. Exclusion criteria included: Pregnant women, Trauma and malignancy.

The following data was collected for each patient: Erythrocyte sedimentation rate (ESR), C-reactive protein (CRP), serology testing, serum urate $\&$ rheumatoid factor and HLA-B27.
Each patient underwent conventional radiography and followed by MRI investigation.

X-rays images was obtained in anteroposterior/ posteroanterior views of SI joints and assessed for features of active sacroiliitis like sclerosis, erosion and joint space.

Criteria: New York sacroiliitis radiological grading criteria of Conventional Radiography is;

Table 1: New York sacroiliitis radiological grading criteria of Conventional Radiography

\begin{tabular}{|l|l|}
\hline Grading & \multicolumn{1}{|c|}{ Criteria } \\
\hline Grade 0 & $\begin{array}{l}\text { No abnormalities (sacroiliac } \\
\text { joints normal) }\end{array}$ \\
\hline Grade 1 & $\begin{array}{l}\text { Suspicious for abnormalities } \\
\text { (blurring of the joint margins) }\end{array}$ \\
\hline Grade 2 & $\begin{array}{l}\text { Minimal abnormalities (solitary } \\
\text { erosions and juxta-articular } \\
\text { sclerosis in small sacral or iliac } \\
\text { areas) }\end{array}$ \\
\hline Grade 3 & $\begin{array}{l}\text { Advanced abnormalities } \\
\text { (manifested juxta-articular } \\
\text { sclerosis, numerous erosions } \\
\text { with widening of joint space, } \\
\text { possible partial ankylosis) }\end{array}$ \\
\hline Grade 4 & \begin{tabular}{l} 
Complete ankylosis \\
\hline
\end{tabular}
\end{tabular}

Magnetic Resonance Imaging: MR imaging was performed at our institute, using a 1.5 $\mathrm{T}$ (Magnetom Symphony with Quantum gradients [maximum gradient amplitude, 30 $\mathrm{mT} / \mathrm{m}$; slew rate, $125 \mathrm{mT} / \mathrm{m} / \mathrm{sec}$; with use of a spine phased-array coil. MR imaging of the sacroiliac joint was performed with coronal oblique T1, T2 and STIR, axial oblique T1, T2 and STIR and sagittal T1 and STIR to identify and evaluate sacroiliitis.

Criteria: MRI images were assessed for the presence of extent and unilateral, active and chronic inflammatory lesions. According to ASAS (Assessment in Spondyloarthritis International Society) criteria, detection of active inflammatory lesions in the form of Bone Marrow Edema (BME) was the grounds for sacroiliitis diagnosis4. Active sacroiliitis findings include- subchondral bone marrow 
edema, erosions, synovitis, joint effusion and capsulitis. Presence of structural lesions (erosions, sclerosis, subchondral fatty change, capsulitis, enthesitis, and bony bridges) alone on MRI in the absence of bone marrow edema is considered insufficient for the diagnosis of active sacroiliitis according to the ASAS criteria, and this is considered to be a prominent limitation.

\section{RESULTS}

Of the 52 patients examined, male preponderance was shown with $31(59.6 \%)$ and $21(40.4 \%)$ were females. Majority of the study population $27(51.9 \%)$ were between 21-30 years of age. All patients complained of low back pain while 50(96\%) with additional findings of restricted spine movement. In the laboratory assessment of the study population, $26(50 \%)$ of them showed elevated CRP, 23(44\%) were HLA B-27 positive and $27(51.9 \%)$ had elevated ESR. Sacroiliac joint involvement on conventional radiography was noticed in $39(75 \%)$ of the patients, with negative findings found in 13 of them. Of the 39 patients with SI joint, 25 presented with unilateral and 14 presented with bilateral involvement. The radiographic findings of SI pathology in the study population presented with sclerosis in $39(75 \%)$, erosion in $3(5.7 \%)$, partial ankylosis in 4(7.7\%) and complete ankylosis in 1(1.9\%) patient. The joint space was narrowed in 19(36.5\%) patients but none of them exhibited widening of the joint space. The New York grading criteria for $\mathrm{X}$ ray diagnosis when performed, it was found that 21 patients had Grade 1(40.4\%), 10 had Grade 2(19.2\%), seven had Grade 3(13.5\%) and 1 (1.9\%) had Grade 4 SI joint involvement. The MRI examination revealed unilateral involvement of SI joint in 34(65.4\%) while bilateral involvement was noticed in $18(34.6 \%)$. MRI examination showed that $52(100 \%)$ patients had bone marrow edema. $8(15.4 \%)$ of them presented edema in sacral aspect, $11(21.2 \%)$ in iliac aspect and $33(63.4 \%)$ in sacro-iliac aspect. Around $42.3 \%$ exhibited bone erosion. Capsulitis was seen in 30(57.7\%). Extracapsular fluid collection was noted in $16(30.7 \%)$ of the patients, while peri articular muscle edema was appreciated in $28(53.8 \%)$ of them. Joint space had widened in nearly half of the patients in $25(48 \%)$ but reduced in $12(23 \%)$ of the study population. MRI findings of study population and comparison of the findings among the study population are shown in Table 2 and 3.

Table 2: MRI findings of the study population.

\begin{tabular}{|c|c|c|}
\hline Variables & NUMBER OF PATIENTS & $\%$ \\
\hline 1) Bone Marrow Edema & 52 & $100 \%$ \\
\hline - Sacro-iliac aspect & 33 & 63.4 \\
\hline - Sacral aspect & 8 & 15.4 \\
\hline - Iliac aspect & 11 & 21.2 \\
\hline 2) Capsulitis & 30 & 57.7 \\
\hline 3) Bone Erosion & 22 & 42.3 \\
\hline 4) Extracapsular Fluid Collection & 16 & 30.7 \\
\hline 5) Peri Articular Muscle Edema & 28 & 53.8 \\
\hline 6) Joint Space & & \\
\hline Normal & 15 & 28.9 \\
\hline Wide & 25 & 48.1 \\
\hline Less & 12 & 23 \\
\hline
\end{tabular}


Table 3: Comparison of MRI findings among the study population

\begin{tabular}{|c|c|c|c|c|}
\hline \multirow[b]{2}{*}{ Variables } & Inflammatory sacroiliitis & Infective sacroiliitis & Chi square & $\mathrm{p}$ value \\
\hline & $\begin{array}{l}\text { Number of patients } \\
\mathrm{N}=24\end{array}$ & $\begin{array}{l}\text { Number of patients } \\
\mathrm{N}=28\end{array}$ & & \\
\hline \multicolumn{5}{|l|}{$\begin{array}{l}\text { Bone Marrow } \\
\text { Edema }\end{array}$} \\
\hline $\begin{array}{l}\text { Sacro-iliac } \\
\text { aspect }\end{array}$ & 13 & 20 & \multirow{3}{*}{10.42} & \multirow{3}{*}{$0.01 *$} \\
\hline Sacral aspect & 1 & 7 & & \\
\hline Iliac aspect & 10 & 1 & & \\
\hline \multicolumn{5}{|l|}{ Capsulitis } \\
\hline Absent & 18 & 4 & \multirow{2}{*}{19.52} & \multirow{2}{*}{$<0.01^{*}$} \\
\hline Present & 6 & 24 & & \\
\hline \multicolumn{5}{|l|}{ Bone Erosion } \\
\hline Absent & 3 & 10 & \multirow{2}{*}{3.71} & \multirow{2}{*}{0.05} \\
\hline Present & 21 & 18 & & \\
\hline \multicolumn{5}{|l|}{$\begin{array}{l}\text { Peri Articular } \\
\text { Muscle Edema }\end{array}$} \\
\hline Absent & 19 & 5 & \multirow{2}{*}{19.55} & \multirow{2}{*}{$<0.01 *$} \\
\hline Present & 5 & 23 & & \\
\hline \multicolumn{5}{|l|}{$\begin{array}{l}\text { Extra } \\
\text { capsular Fluid } \\
\text { Collection } \\
\end{array}$} \\
\hline Absent & 24 & 12 & \multirow{2}{*}{16.48} & \multirow{2}{*}{$<0.01 *$} \\
\hline Present & 0 & 16 & & \\
\hline \multicolumn{5}{|l|}{ Joint Space } \\
\hline Normal & 10 & 4 & \multirow{3}{*}{13.27} & \multirow{3}{*}{$0.001 *$} \\
\hline Wide & 5 & 20 & & \\
\hline Less & 9 & 4 & & \\
\hline
\end{tabular}

*: statistically significant

\section{DISCUSSION}

All the study participants presented with chronic back ache $52(100 \%)$ followed by the restricted spinal movement 50(96\%), morning stiffness in $18(34.6 \%)$ and pain relieved on exercise in $20(38.5 \%)$ at the time of study. These results were similar to the study done by Rudwaleit et al. in which majority of their study population (patients with Axial SpA) had back pain for 6- 7 years and pain relieved on exercise and not upon rest in one third of their study subjects. ${ }^{5}$ In the study, Sacroiliitis was more common in age $21-40$ years $(75.6 \%)$. Sacroiliitis showed a male predominance with male to female ratio of $1.6: 1$. The study conducted by Carmona et al. ${ }^{6}$ also presented similar findings. HLA B-27 positivity is extremely relevant to the early diagnosis of SpA. Five to $10 \%$ of the population are HLA B-27 positive and in patients with AS and SpA the positivity of HLA B-27 changes to $70 \%$ to $95 \%$ and nearly $70 \%$, respectively. ${ }^{8}$ Nearly half of the patients $24(46.1 \%)$ of the present study reported with HLA-B 27 positive. Studies have shown an association between HLA-B27-positive patients, who had a significantly higher degree of both acute and chronic MRI changes compared with HLAB27-negative patients. This may imply that inflammatory attacks in HLA-B27 positive 
patients occur mainly at the beginning of the disease process. The probability of SpA was increased in HLA-B27 positive patients with inflammatory lower backache and MRI proven sacroiliitis. ${ }^{9}$ Increased inflammatory activity, is defined by an elevated ESR ( $>15$ $\mathrm{mm} /$ hour) was present in $27(51.9 \%)$ patients in the study population. This was almost similar to the study conducted by Ahlstrom et al. ${ }^{10}$ Elevated CRP may indicate the possibility of active inflammation at the sacroiliac joint pathologies detectable by MRI, which is consistent with other studies. ${ }^{11}$ Conventional radiography: New York criteria was the grading system used as the criteria for identifying sacroiliac joint disease in Conventional radiography in our study. Other studies like Weber et al. also included same criteria to diagnose sacroiliitis owing to its making it a standard reference. ${ }^{12}$ Using the New York criteria, conventional radiographs showed involvement of the sacroiliac joint in $39(75 \%)$ patients out of 52 . Unilateral involvement was seen in $25(48 \%)$ patients and bilateral involvement was detected in $14(27 \%)$ patients. $7(13.5 \%)$ patients were shown to have partial ankylosis of the sacroiliac joint and one patient showed the complete ankylosis. In a similar study, all 18 patients reported with sacroiliac joint involvement, with unilateral involvement seen in one patient and bilateral involvement in 17 patients. In a study by Miriam et al. ${ }^{13} 1$ patient $(1.19 \%)$ reported with complete ankylosis while 7 patients in the study showed partial ankylosis, which is slightly higher than our study. Magnetic Resonance Imaging: It seems to be superior to other imaging modalities in the diagnosis of active sacroiliitis due to the evaluation of bone marrow and extracapsular changes. MRI is capable of visualization of early active inflammatory changes of the sacroiliitis, so the early diagnosis of sacroiliitis is usually established by MRI. ${ }^{14}$ All 52 patients presented abnormal MRI findings of sacroiliac joint pathologies in the present study, with 34 patients having bilateral involvement and 18 patients presenting unilateral involvement. On comparing with other studies, Miriam et al. ${ }^{13}$ reported all 18 patients except one having abnormal MRI findings of the sacroiliac joint: $16(88.9 \%)$ patients had bilateral involvement and $1(9.1 \%)$ patient had unilateral involvement. $52(100 \%)$ patients in the current study demonstrated bone marrow edema. These changes were seen in patients with MRI findings suggestive of active disease. ${ }^{4} \mathrm{~A}$ study conducted by Braun et al. ${ }^{15}$ of SI joint imaging by MRI demonstrated that the technique could be used to detect early abnormalities in the subchondral bone and periarticular bone marrow. Of the 52 patients, 24 were diagnosed as seronegative spondyloarhtritis and 28 as infective sacroiliitis. In the present study, bone marrow edema was observed in 52 patients, out of which 24 and 28 fall in the inflammatory and infective sacroiliitis respectively. Bone marrow edema was noted on the sacral aspect or iliac aspect or on both the aspects. 13(25\%), $1(1.9 \%)$ and $10(21.2 \%)$ subjects of inflammatory sacroiliitis were reported showing bone marrow edema involving sacro-iliac, sacral and iliac aspects respectively, while in patients of infective sacroiliitis the distribution of bone marrow edema was $20(38.5 \%)$ on sacroiliac aspect, $7(13.5 \%)$ on sacral aspect and $1(1.9 \%)$ on iliac aspect. When bone marrow edema categories were compared statistically according to inflammatory and infective sacroiliitis, it was found to be statistically significant. On comparison our study is concordance with that of Yushuhn et al. ${ }^{16}$ which also showed the distribution of bone marrow edema showing statistically significant difference between infectious and spondyloarthritis $(\mathrm{p}<0.001)$. Capsulitis was present in $6(11.5 \%)$ and $24(46.1 \%)$ subjects of inflammatory and infective sacroiliitis respectively with statistically significant difference $(p<0.01)$. When periarticular muscle edema was the sole predictor, unilateral sacroiliitis in spondyloarthritis was correctly identified in $79.16 \%$ of cases, and infectious sacroiliitis was correctly identified in $82.14 \%$ of cases with an overall accuracy 
of $80.7 \%$. Extracapsular Fluid collection was noted exclusively in infective sacroiliitis and widening of joint space more frequently in infective sacroiliitis. Similar findings were noted with the study by Carita Tsoi et al. ${ }^{17}$ inflammation in infective sacroiliitis spreads to involve the peri-articular soft tissues, particularly the iliacus and gluteal muscles. Peri-articular fluid collection or abscess is practically pathognomonic of an infective sacroiliitis. In a study by Klein et al. ${ }^{18}$, all the cases of infectious sacroiliitis showed fluid or inflammation in the iliopsoas muscle that tracked posterior to the iliopsoas muscle. Le Breton et al. ${ }^{19}$ reported that swelling of the muscles around the sacroiliac joint, which appeared as a decrease of fat between the iliacus and the psoas muscles, could confirm the diagnosis of infectious sacroiliitis. Our study results show that the presence of bone erosion, capsulitis, extracapsular fluid collection, and periarticular muscle edema on MRI suggest infectious sacroiliitis, whereas iliac-dominant bone marrow edema favor the diagnosis of sacroiliitis in spondyloarthritis. MRI allows an early diagnosis of sacroiliitis (before cortical erosions and subchondral sclerosis appears) because it can detect inflammatory changes that are the hallmark of early disease. MRI can depict active inflammatory lesions and structural damage lesions. ${ }^{20}$ Comparison of conventional x-rays with MRI: the study demonstrates that use of MRI in visualizing and staging sacroiliitis by MRI is better than conventional radiography. This finding is similar to the study conducted by Jurgen Braun et al. ${ }^{15}$, Shanmuganandhan et al. ${ }^{21}$ which concluded that early sacroiliitis can be demonstrated by dynamic MRI in spondyloarthropathy patients in whom abnormalities were not revealed by conventional radiography. Though different radiological methods have been used to examine Sacroiliac joint pathologies, MRI is getting increasingly preferred over conventional radiography and even CT because of its ability to detect inflammatory changes. In addition, MRI has the advantage of no radiation exposure. Taking all aspects of sacroiliitis into consideration, MRI has found to be significantly superior to conventional radiography for the diagnosis of sacroiliitis. Plain radiographs have been used conventionally for the diagnosis of SpA. However, they have been considered to report lack of positivity rates in early disease as it may over 8 years for the sacroiliitis to become visible. Diagnostic criteria of AS are based on the presence of sacroiliitis on plain radiographs hence early cases may be missed. Radiography cannot reveal the cartilage changes and bone marrow oedema, which can be seen in MR images. Due to the ability to image cartilage changes and bone marrow oedema directly, MR imaging may be particularly useful in early diagnosis of sacroiliitis. ${ }^{21,22,23,24} \mathrm{New}$ treatment options for patients with ankylosing spondylitis require sensitive imaging techniques to not only help diagnose ankylosing spondylitis early, but also determine disease activity and the degree of damage present at diagnosis. ${ }^{25}$ Also several trials have shown that MRI is not only capable of finding structural lesions, but they can also detect active inflammatory lesions, unlike X-Ray which can only detect structural lesions. ${ }^{26}$ The data adds to the hypothesis that inflammation is the first event, and structural change is a subsequent feature. Depending on the lag time between inflammation and structural changes, a diagnosis of sacroiliitis could be made significantly earlier by using MRI changes of inflammation as an early sign of disease. ${ }^{7}$ Representative imaging findings are shown on illustrated in figures 1-3.

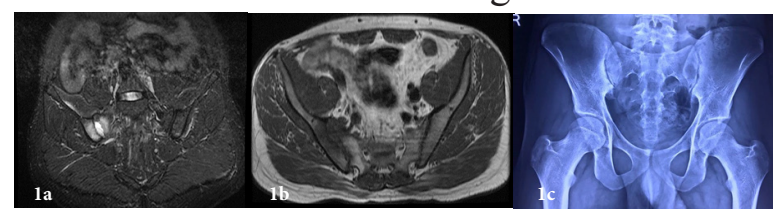

Figure 1. 35 year old male patient diagnosed as infective sacroiliitis 1a. Coronal STIR image showing the bone marrow edema involving the iliac and sacral aspect of the right SIJ. Adjacent periarticular muscle edema and fluid signal intensity in the widened right SIJ space s/o capsulitis $\mathbf{1 b}$. Axial image showing the bony erosion involving the right 
SIJ involving both the sacral and iliac aspect. 1c. X-ray AP view of bilateral SIJ shows sclerosis of the right SIj mainly the iliac side.

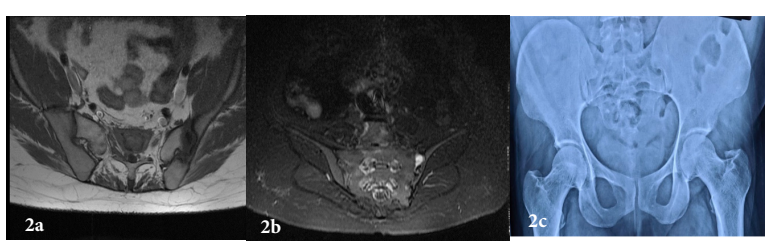

Figure 2. 28 Year old female diagnosed as infective sacroiliitis 2a.T1 image bilateral SIJ showing the bony erosion seen involving the iliac aspect of Left SIJ $2 \boldsymbol{b}$. MRI Coronal image of SIJ showing extracapsular collection around the left sacroiliac joint 2c. Xray-AP view of Bilateral SIJ of same patient showing the diminished joint space bilaterally.

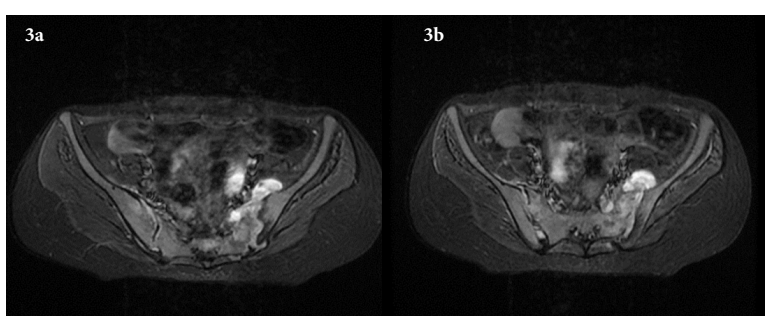

Figure 3. 23 Year old female diagnosed as bilateral infective sacroiliitis $3 \boldsymbol{a} \& \mathbf{3} \boldsymbol{b} . M R I$ axial stir images showing the extracapsular fluid collection adjacent to the left sacroiliac joint with fluid signal intensity in the left sacroiliac joint space and periarticular muscle edema (Iliacus) on the right side.

\section{CONCLUSION}

Thus, from our study we conclude that conventional radiography and MRI both can be used for the diagnosis of sacroiliitis. However, conventional radiography can be used as a screening tool and follow-up of patients with sacroiliitis. The main limitation of the x-ray film is the low sensitivity for detecting abnormalities in early stages of the disease. MRI plays an essential role in better demonstrating early alterations and inflammatory activity of this process. MRI can identify both inflammation and structural changes caused by inflammation, while radiographs only detect structural changes. MRI findings of extensive extracapsular soft- tissue abnormalities, periarticular muscle edema, capsulitis, and extracapsular fluid collections and bone erosion may enable reliable differential diagnosis of infectious sacroiliitis from sacroiliitis associated with spondyloarthritis, whereas the presence of iliac-dominant bone marrow edema and supports the diagnosis of spondyloarthritis.

\section{CONFLICT OF INTEREST}

None

\section{SOURCES OF FUNDING}

None

\section{REFERENCES}

1. Buchanan BK, Varacallo M. Sacroiliitis. StatPearls 2020. Available from: https:// www.ncbi.nlm.nih.gov/pmc/articles/ PMC7388811/ [Accessed 19th February 2020].

2. Chahal BS, Kwan AL, Dhillon SS et al. Radiation exposure to the sacroiliac joint from low-dose CT compared with radiography. AJR Am J Roentgenol 2018:1058-62. https://doi.org/10.2214/ AJR.18.19678

3. Gutierrez M, Rodriguez S, Soto-Fajardo $\mathrm{C}$ et al. Ultrasound of sacroiliac joints in spondyloarthritis: a systematic review. Rheumatol. Int 2018;38(10):1791-805. https://doi.org/10.1007/s00296-0184126-X

4. Montandon C, Costa MA, Carvalho TN, Júnior ME, Teixeira KI. Sacroiliitis: imaging evaluation. Radiol Bras 2007;40(1):53-60. https://doi.org/10.1590/S0100$\underline{39842007000100012}$

5. Dougados $\mathrm{M}$, Linden $\mathrm{SV}$, Juhlin $\mathrm{R}$ et al. The European Spondylarthropathy Study Group preliminary criteria for the classification of spondylarthropathy. Arthritis Rheum 1991;34(10):1218-27. https://doi.org/10.1002/art.1780341003

6. Carmona R, Harish S, Linda DD, Ioannidis $\mathrm{G}$, Matsos M, Khalidi NA. MR imaging of the spine and sacroiliac 
joints for spondyloarthritis: influence on clinical diagnostic confidence and patient management. Radiology 2013;269(1):208-15. https://doi. org/10.1148/radiol.13121675

7. Heuft-Dorenbosch L, Landewe R, Weijers $\mathrm{R}$ et al. Combining information obtained from magnetic resonance imaging and conventional radiographs to detect sacroiliitis in patients with recent onset inflammatory back pain. Ann Rheum Dis 2006;65(6):804-8. https:// doi.org/10.1136/ard.2005.044206

8. Akgul O. Classification criteria for spondyloarthropathies. World J Orthop 2011. https://doi.org/10.5312/wjo. $\mathrm{v} 2.112 .07$

9. Puhakka KB, Jurik AG, Egund $\mathrm{N}$ et al. Imaging of sacroiliitis in early seronegative spondylarthropathy. Assessment of abnormalities by MR in comparison with radiography and CT. Acta Radiol 2003;44:218-29. https://doi. org/10.1034/j.1600-0455.2003.00034.x

10. Ranga A, Agarwal Y, Meena VK, Chopra RK. Comparison of radiography, computed tomography and magnetic resonance imaging in the detection of sacroiliitis in ankylosing spondylitis. Astrocyte 2016;2:179-84. https://doi. org/10.4103/2349-0977.191042

11. Dougados M, Maksymowych WP, Landewé RBM et al. Evaluation of the change in structural radiographic sacroiliac joint damage after 2 years of etanercept therapy (EMBARK trial) in comparison to a contemporary control cohort (DESIR cohort) in recent onset axial spondyloarthritis. Ann Rheum Dis 2018;77:221-7. https://doi.org/10.1136/ annrheumdis-2017-212008

12. Puhakka KB, Jurik AG, Egund $\mathrm{N}$ et al. Imaging of sacroiliitis in early seronegative spondylarthropathy: assessment of abnormalities by MR in comparison with radiography and CT. Acta Radiologica 2003;44(2):218-
29. $\quad$ https://doi.org/10.1034/j.16000455.2003.00034.x

13. Bredella MA, Steinbach LS, Morgan S, Ward M, Davis JC. MRI of the sacroiliac joints in patients with moderate to severe ankylosing spondylitis. $\mathrm{Am}$ $J \quad$ Roentgenol 2006;187(6):1420-6. https://doi.org/10.2214/AJR.05.1423

14. Jee WH, McCauley TR, Lee SH, Kim SH, Im SA, Ha KY. Sacroiliitis in patients with ankylosing spondylitis: association of MR findings with disease activity. Magn Reson Imaging 2004; 22:245-50. https://doi.org/10.1016/j. mri.2003.09.002

15. Braun J, Bollow M, Eggens U, König H, Distler A, Sieper J. Use of dynamic magnetic resonance imaging with fast imaging in the detection of early and advanced sacroiliitis in spondylarthropathy patients. Arthritis \& Rheumatism: Official Journal of the American College of Rheumatology 1994;37(7):1039-45. https://doi. org/10.1002/art.1780370709

16. Kang Y, Hong SH, Kim JY et al. Unilateral sacroiliitis: differential diagnosis between infectious sacroiliitis and spondyloarthritis based on MRI findings. Am $J$ Roentgenol 2015;205(5):1048-55. https://doi. org/10.2214/AJR.14.14217

17. Tsoi C, Griffith JF, Lee RK, Wong PC, Tam LS. Imaging of sacroiliitis: Current status, limitations and pitfalls. Quant Imaging Med Surg 2019;9(2):318$35 . \quad$ https://doi.org/10.21037/ qims.2018.11.10

18. Klein MA, Winalski CS, Wax MR, Piwnica-Worms DR. MR imaging of septic sacroiliitis. J Comput Assit Tomogr 1991;15(1):126-32. https://doi. org/10.1097/00004728-199101000$\underline{00020}$

19. Le Breton C, Frey I, Carette MF et al. Infectious sacroiliitis: value of 
computed tomography (CT) and magnetic resonance imaging (MRI). European Radiology 1992;2(3):233-9. https://doi.org/10.1007/BF00595836

20. Prakash J. Sacroiliac tuberculosis-a neglected differential in refractory low back pain-our series of 35 patients. $J$ Clin Orthop Trauma 2014;5(3):146$53 . \quad$ https://doi.org/10.1016/j. jcot.2014.07.008

21. Shanmuganandan K, Shankar S, Grover R, Sridhar CM, Sreeram MN, Raphael J. A comparative evaluation of MRI, radionucleide bone scan and plain radiographs in Indian patients with spondyloarthropathy. Indian $J$. Rheumatol 2006;1(2):53-9. https://doi. org/10.1016/S0973-3698(10)60004-0

22. ÇALIŞIR C, Korkmaz C, Kaya T. Comparison of MRI and $\mathrm{CT}$ in the Diagnosis of Early Sacroiliitis. Medical Journal of Kocatepe.2006;6:49-56. Available from https://kocatepetipdergisi.aku.edu.tr/ PDF/Ocak\%202006/09 \%2049-56 Cuneyt $\% 20$ Calisir.pdf [Accessed 21st February 2020].

23. Van der Heijde D, Landewé R. Imaging in spondylitis. Curr Opin Rheumatol 2005;17(4):413$7 . \quad$ https://doi.org/10.1097/01. bor. $0000163195.48723 .2 \mathrm{~d}$

24. Galasko CSB, Weber DA. The arthritides. In: Galasko CSB, editor. Radionuclide Scintigraphy in Orthopaedics. Edinburgh: Churchill Livingstone 1984.

25. Illescas MB, Menéndez CL, Rodríguez MR, Quintero RF. New ASAS criteria for the diagnosis of spondyloarthritis: diagnosing sacroiliitis by magnetic resonance imaging. Radiología 2014;56(1):7-15. https://doi. org/10.1016/j.rx.2013.05.004

26. Kang Y, Hong SH, Kim JY et al. Unilateral sacroiliitis: differential diagnosis between infectious sacroiliitis and spondyloarthritis based on MRI findings. Am $J$ Roentgenol 2015;205(5):1048-55. https://doi. org/10.2214/ajr.14.14217 